\title{
An Analysis of the Physical Characteristics of the Summer Low Atmosphere in the Gobi Desert Adjacent to Bosten Lake, Xinjiang, China
}

\author{
Yan Li $\mathbb{D}^{1,2}$ Xuejin Sun ${ }^{10},{ }^{1}$ Hui Ning, ${ }^{2}$ Hongcai Qin, ${ }^{2}$ and Jiuquan Zhao $^{2}$ \\ ${ }^{1}$ College of Meteorology and Oceanography, National University of Defense Technology, Nanjing 211101, China \\ ${ }^{2}$ Northwest Institute of Nuclear Technology, Xian 841700, China \\ Correspondence should be addressed to Xuejin Sun; xjsun2002@sina.com
}

Received 15 November 2017; Accepted 7 December 2017; Published 8 January 2018

Academic Editor: Enrico Ferrero

Copyright (C) 2018 Yan Li et al. This is an open access article distributed under the Creative Commons Attribution License, which permits unrestricted use, distribution, and reproduction in any medium, provided the original work is properly cited.

A month-long field observation campaign was conducted, which covered approximately $100 \mathrm{~km}^{2}$ of the Gobi Desert area on the southeast bank of Bosten Lake during the summer of 2016. The purpose of the study was to examine the physical characteristics of the low atmosphere over land-lake nonuniform underlying surfaces in the Gobi Desert of northwestern China. The results of the statistical analysis showed that, during the observational period, the average daytime surface horizontal thermal gradient reached up to $-0.2^{\circ} \mathrm{C} / \mathrm{km}$ from the lakeshore to southern Gobi Desert area. The near-surface wind field of the $7 \mathrm{~km}$ horizontal extent from the lakeshore was dominated by onshore breezes with average peak wind speeds above $5 \mathrm{~m} / \mathrm{s}$. In the atmospheric near-surface layer, an isohumidity layer at a height between 10 and $50 \mathrm{~m}$ a.g.l. was observed from 11:00 to 18:00 LST. Also, a case study for the atmospheric boundary layer and local circulation analyses was conducted. The onshore breezes were found to play a major role in the vertical structure of the local atmospheric boundary layer. The numerical simulation results indicated that there was an alternating day-night local circulation in the Bosten Lake area.

\section{Introduction}

China's Xinjiang Uygur Autonomous Region is located far from the ocean, in the Eurasian hinterland. The Tianshan Mountains, which stretch from west to east, divide Xinjiang into two parts, namely, southern Xinjiang and northern Xinjiang $[1,2]$. Due to the blocking effects of the Tianshan Mountains, the precipitation is concentrated in the Tianshan mountainous area and northern Xinjiang. Meanwhile, southern Xinjiang is mainly covered by the arid Gobi Desert [35]. Bosten Lake is located in the southern Xinjiang Yanqi Basin, adjacent to the northeastern edge of the Taklimakan Desert. It is the largest inland fresh-water lake in China and measures approximately $55 \mathrm{~km}$ in length from east to west and $20 \mathrm{~km}$ in width from south to north. The average waterdepth is $7.5 \mathrm{~m}$ [6]. Its abundant fresh-water resources play an important role in the ecological environment, as well as the regional socioeconomic development [7].
The southern bank of Bosten Lake is located far from any towns and is almost entirely covered by the Gobi Desert. This area has a relatively flat underlying surface, which provided good conditions for the examination of the physical characteristics of the low atmosphere under the influence of lake-land nonuniform underlying surfaces within the Gobi Desert. Significant temperature differences have been observed between the lake (cool) and the land (warm) surfaces during daytime, especially during the summer seasons when calm synoptic conditions often prevail in southern Xinjiang. Since the beginning of this century, atmospheric observations have been carried out in a planned way in this area. However, earlier observational data are relatively sparse.

In addition to direct field observations, numerical simulations are also one of the powerful methods utilized to study atmosphere-land interactions [8-11]. Mesoscale numerical weather models have been found to effectively simulate the complex thermal-dynamical processes in the atmospheric 


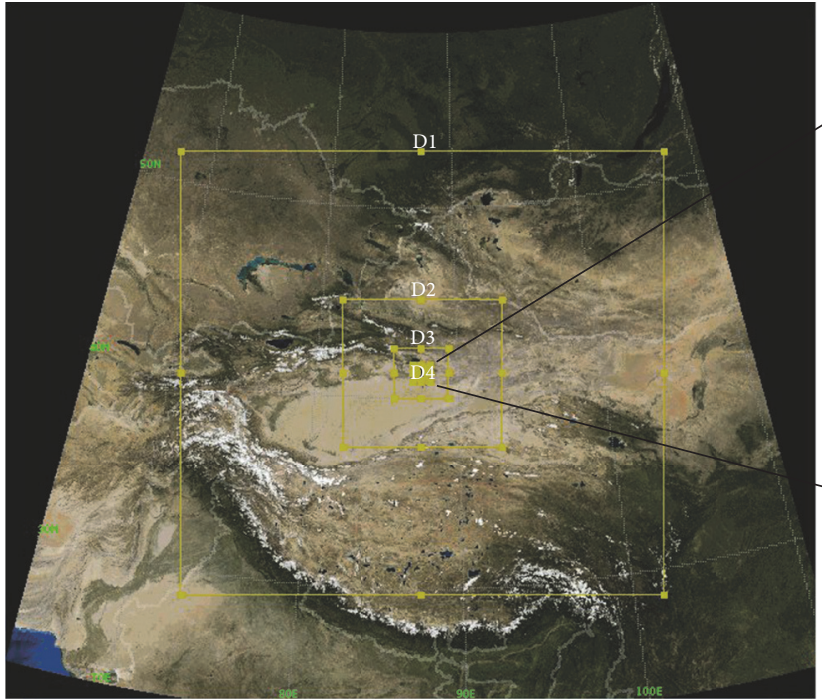

(a)

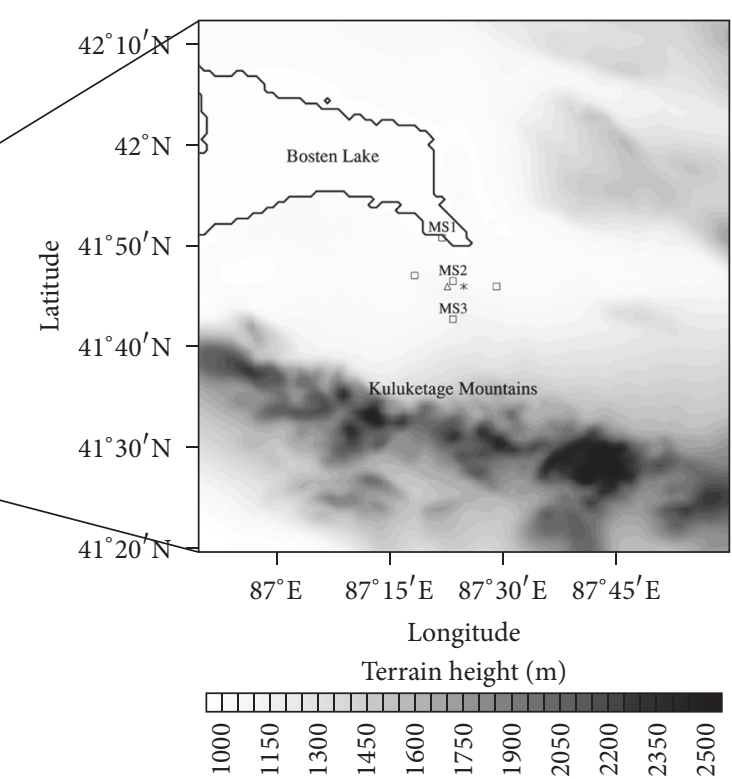

- Meteorological station

* Radiosonde

$\Delta$ Meteorological tower

(b)

FIGURE 1: Domain setting of the WRF model (a); innermost domain terrain; and observational equipment layout (b).

boundary layer (ABL), which has been successfully applied in the study of regional circulations. Samuelsson and Tjernström used a three-dimensional mesoscale model to show that the main influence factor of the boundary layer flow pattern of Tamnren Lake, which has a water area of only $34 \mathrm{~km}^{2}$, was the difference in the surface roughness between the lake and the land [12]. Meanwhile, with the help of a nonhydrostatic mesoscale model, Stivar et al. showed that lake breezes caused by the differences in the lake-land temperatures had significant effects on the local circulation in the Itaipu Lake area [13]. Recently, the state-of-the-art Weather Research and Forecasting (WRF) model was applied to simulate the complex structures of low atmosphere flow fields [14-16].

The aim of this study was to discuss the physical characteristics of low atmospheres under the influence of lakeland surface heterogeneity during the summer season in the Gobi Desert of northwestern China. For this purpose, a month-long field observation campaign was conducted which covered approximately $100 \mathrm{~km}^{2}$ of the Gobi area. Also, the WRF model was used to simulate the diurnal evolution of the breeze circulations over the lake area for a selected case study.

\section{Data and Methods}

2.1. Study Area and the Meteorological Observational Data. This study's observational area was approximately $100 \mathrm{~km}^{2}$ located on the southeast bank of Bosten Lake, which was characterized by an elevation which rose gradually from the lakeshore to the south and flat strip-like terrain from east to west (as shown in Figure 1). The average terrain height was approximately $1,100 \mathrm{~m}$ a.s.l., and the land surface was covered with sparse Gobi vegetation. The elevated peaks to the south of Bosten Lake were the Kuluketage Mountains, which presented a rather unique condition for the development of breezes. It was observed that the onshore breeze, acting in phase with the slope winds, generated stronger and more persistent flow fields [17]. Numerical experiments also showed that inland elevated terrain tends to significantly strengthen the offshore breeze part of local diurnal circulations, as compared to the case without terrain [18]. The observation campaign spanned from July 15 to August 15, during the summer season of 2016. Precipitation only occurred on August $8(27 \mathrm{~mm})$ in the study area, which was excluded from the analysis.

The observational instrumentation in the study area mainly included a surface meteorological variable distribution measurement system (SMVDMS), along with a meteorological tower, which were used to measure the horizontal and vertical gradient of meteorological variables in the atmospheric near-surface layer. Also, boundary layer sounding equipment was used in the observations. Figure 1 shows the equipment layout in the study area. The SMVDMS included a total of five surface meteorological stations. These stations provided daily observations of the $2 \mathrm{~m}$ temperature, $2 \mathrm{~m}$ airpressure, $2 \mathrm{~m}$ relative humidity, and $10 \mathrm{~m}$ wind. Among these meteorological stations, one set was located at the center of the study area (MS2). The others were located in the north (MS1) and south (MS3), as well as in the east and west, at 6.8 to $7.4 \mathrm{~km}$ away from the MS2, respectively. The MS1 was located close to Bosten Lake. During the observational 
TABLE 1: WRF domain settings used in the present study.

\begin{tabular}{lccc}
\hline Domain & Horizontal resolution $/(\mathrm{km})$ & Grid points & Time-step/(s) \\
\hline D1 & 27 & $100 \times 100$ & 162 \\
D2 & 9 & $100 \times 100$ & 54 \\
D3 & 3 & $100 \times 100$ & 18 \\
D4 & 1 & $100 \times 100$ & 6 \\
\hline
\end{tabular}

period, the data collection intervals for the temperature, relative humidity, wind direction, and wind speed were all set at $10 \mathrm{~s}$.

The meteorological tower was $100 \mathrm{~m}$ high, and sensors were mounted at heights of $10 \mathrm{~m}, 20 \mathrm{~m}, 35 \mathrm{~m}, 50 \mathrm{~m}, 70 \mathrm{~m}$, $80 \mathrm{~m}$, and $100 \mathrm{~m}$ above the ground, respectively. Each height was equipped with temperature and humidity sensors, as well as three-dimensional ultrasonic wind sensors. Meanwhile, the air-pressure sensors were only mounted at the 10 and $100 \mathrm{~m}$ heights. The temperature, air-pressure, and relative humidity data were stored at $60 \mathrm{~s}$ sampling intervals and a three-dimensional velocity of $10 \mathrm{~s}$. Then, one set of permanently installed L-band radiosonde radar and one GPS sounding system (located next to the MS1) were applied in the atmospheric boundary layer soundings for a selected case study. This study's sample height interval of radiosonde was $50 \mathrm{~m}$, while the GPS sounding was continuously stored at one second intervals.

2.2. WRF Description and Setup of the Model. The mesoscale numerical weather prediction (NWP) model which was used in this study was the WRF model version 3.6, with an Advanced Research WRF (ARW) dynamic solver developed primarily at the National Center for Atmospheric Research (NCAR) $[19,20]$. The WRF model is a powerful NWP and atmosphere simulation model, and its numerous physics and dynamic packages have been contributed to by a broad scientific community. As a fully compressible and nonhydrostatic model, the WRF allows for high spatial resolution for a particular region, which made it a suitable choice for this study. A numerical simulation experiment was run with four nested domains. Table 1 summarizes the model domain settings. The outmost domain (D1) covered China's Xinjiang Province, Qinghai-Tibet Plateau, and western Mongolia Plateau. Meanwhile, the finest grid domain (D4) covered most of Bosten Lake, along with the entire target area of the present study, as shown in Figure 1. The same grid number was used for each domain in order to ensure sufficient transition space between the parent and nest domain. Each domain contained 33 vertical stretching levels, with the toplevel set at $100 \mathrm{hPa}$. There were 17 levels within the height of $1.2 \mathrm{~km}$ above the ground, of which the grid points of the first level were located at the height of approximately $17 \mathrm{~m}$.

The WRF physical parameterization schemes used in this simulation included the following: the Yonsei University (YSU) Planetary Boundary layer scheme and the Mesoscale Model-5 (MM5) surface layer scheme. As a nonlocal closure scheme which considered the entrainment, it was found that the YSU displayed good simulation effects on both the daytime convective boundary layer and the nighttime stable

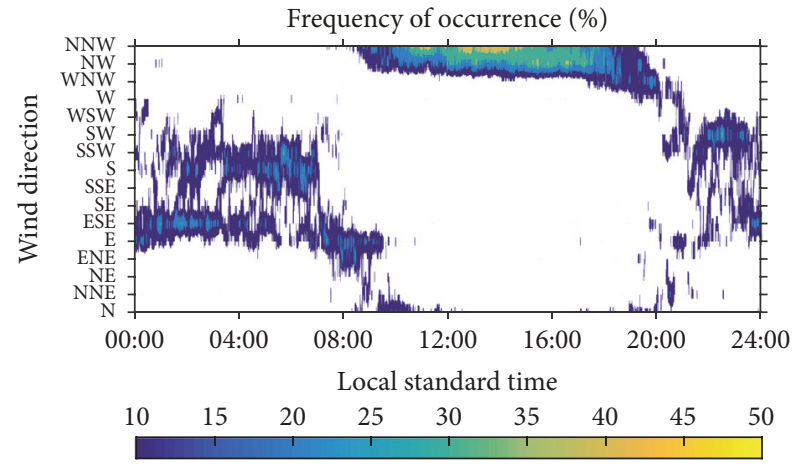

FIgURE 2: Distribution of the wind directions as a function of the time of day (LST) recorded in the observation area. The color bar shows the frequency of the occurrences (\%).

boundary layer [21-23]. A Noah scheme was adopted as the land surface model, in order to provide the surface flux for the YSU, which calculated the soil temperature and moisture in four layers. Other physical schemes included a WRF SingleMoment 3-class (WSM3) scheme for microphysics; a Rapid Radiative Transfer Model (RRTM) for longwave radiation; a Dudhia scheme for shortwave radiation; and a Kain-Fritsch cumulus parameterization scheme.

The initial and boundary conditions were provided by $1^{\circ} \times 1^{\circ}$ NCEP Global Final (FNL) Operational Model Global Tropospheric Analyses (https://rda.ucar.edu/datasets/ds083.2/), which was made available at every $6 \mathrm{~h}$ interval. Then, the acquired Advanced Space Borne Thermal Emission and Reflection Radiometer Global Digital Elevation Model (ASTER GDEM) digital elevation data were used as the terrain data, with a resolution of $1^{\prime \prime}$. This study's simulation was cold-started at 00:00 UTC ( $\mathrm{LST}=\mathrm{UTC}+6 \mathrm{~h}$ ) on August 11,2016 . It continuously ran for thirty-six hours, with a model output interval of nine minutes. The first 12 -hour model simulation was for the "spin-up" process, due to the initial relatively coarse-resolution conditions.

\section{Results}

3.1. Analysis of the Near-Surface Meteorological Variables. This section details the impact of Bosten Lake on the local climate.

At ground level, the diurnal variation of wind field was apparent. Figure 2 shows the distribution of the wind direction as a function of the time of day in the study area, which was obtained from SMVDMS data. The winds were divided into 16 directions, with intervals of $22.5^{\circ}$. The 


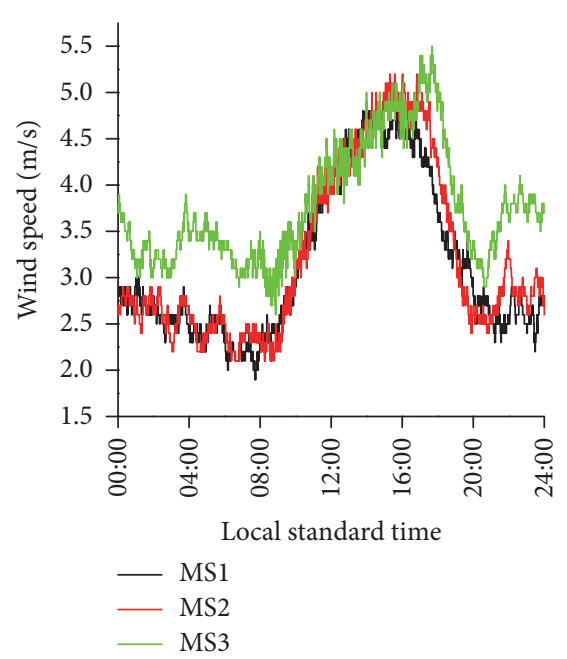

(a)

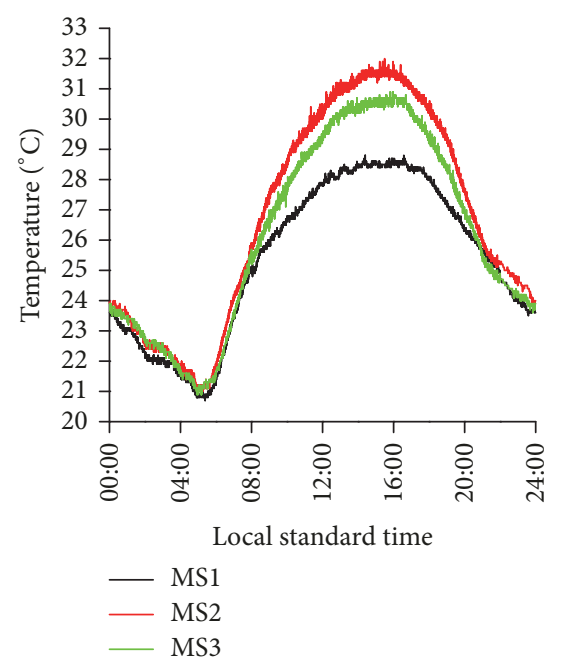

(b)

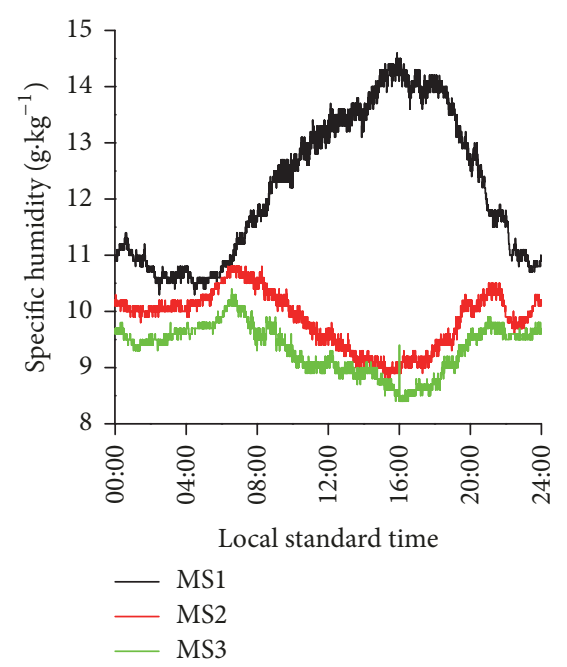

(c)

FIGURE 3: Average diurnal change curves of (a) the ground-level wind speeds; (b) temperature; and (c) specific humidity, measured by the surface meteorological stations in the observational area.

direction of the surface wind fields showed quite a significant diurnal pattern, in which they were well focused in the north in the midmorning and afternoon (N-NW from 09:00 to 20:00 LST, onshore breezes), while at the night and earlymorning the winds were more diffuse. However, a major part originated from the south (SW-ESE from 22:00 to 07:00 LST).

Figure 3 shows the averages of wind speeds, temperatures, and specific humidity as a function of the time of day, which were recorded by the MS1, MS2, and MS3 meteorological stations during the observational period. Figure 3(a) shows that the onshore breezes developed from 09:00 to 16:00 LST, as well as the higher wind speeds associated with the onshore breezes with respect to the nocturnal breezes, with the peak speed reaching approximately $5 \mathrm{~m} / \mathrm{s}$. The change curve comparison between the meteorological stations showed that the onshore breeze could potentially dominate the local wind regime by a horizontal extent of more than $7 \mathrm{~km}$ from the lakeshore (where the MS2 was located). However, further southwards at the MS3 location, the influence of wind flows in the mountainous area was prominent.

Figure 3(b) shows the cold-island effects of Bosten Lake, where the daytime temperatures recorded by the MS1 were found to be obviously lower than those of the MS2 and MS3. Also, the average horizontal thermal gradient reached up to $-0.2^{\circ} \mathrm{C} / \mathrm{km}$ in the north-south direction, which was favorable for triggering onshore breezes. However, the nocturnal temperature changes of the MS1, MS2, and MS3 were determined to be almost the same, which indicated that radiation cooling played a dominant role in the nighttime Gobi Desert.

As viewed from the contrast in the specific humidity change curves detailed in Figure 3(c), the existence of Bosten Lake obviously altered the distribution and diurnal changes in the moisture above the Gobi Desert's lakeshore area. Due to the continuously transportation of water vapor by the onshore breezes, the surface moisture close to the lakeshore

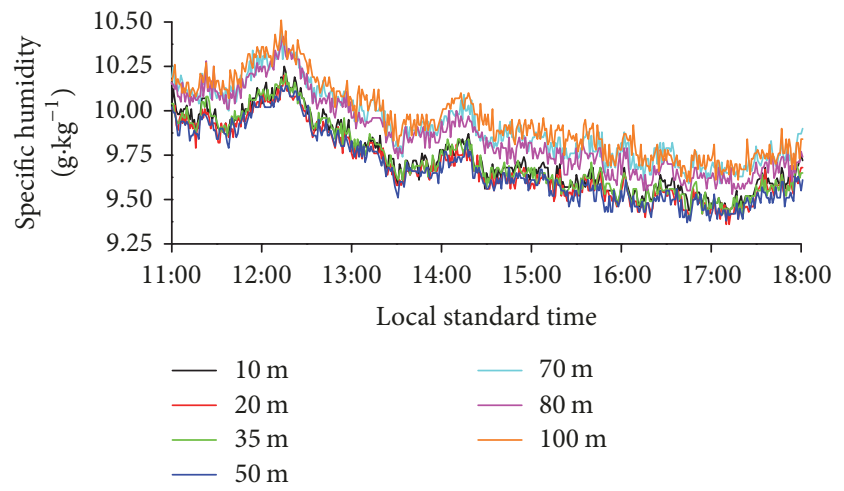

FIGURE 4: Contrast diagram of the average time-varying curves of specific humidity at the different heights of the meteorological tower.

increased after sunrise until approximately 16:00 LST (note: at the same time, the moisture level dropped in the southern Gobi Desert), and a positive horizontal humidity gradient existed from north to south.

Figure 4 shows the average specific humidity at different heights as a function of the time of day, which were recorded by the meteorological tower. In order to show the structure details more clearly, vertical profiles of the average specific humidity at different times from Figure 4 are presented in Figure 5. It can be seen from Figures 4 and 5 that the atmospheric near-surface layer appeared to have inverse humidity between 11:00 and 18:00 LST. During that time, an isohumidity layer between $10 \mathrm{~m}$ and $50 \mathrm{~m}$ a.g.l. was observed.

Figure 6(a) shows that the wind speed vertical gradient of the onshore breezes was smaller than that of the nocturnal breezes. The minimum value appeared at approximately 09:00 LST, which was a result of the breeze transition and atmospheric turbulence mixing. Equation (1) was used 


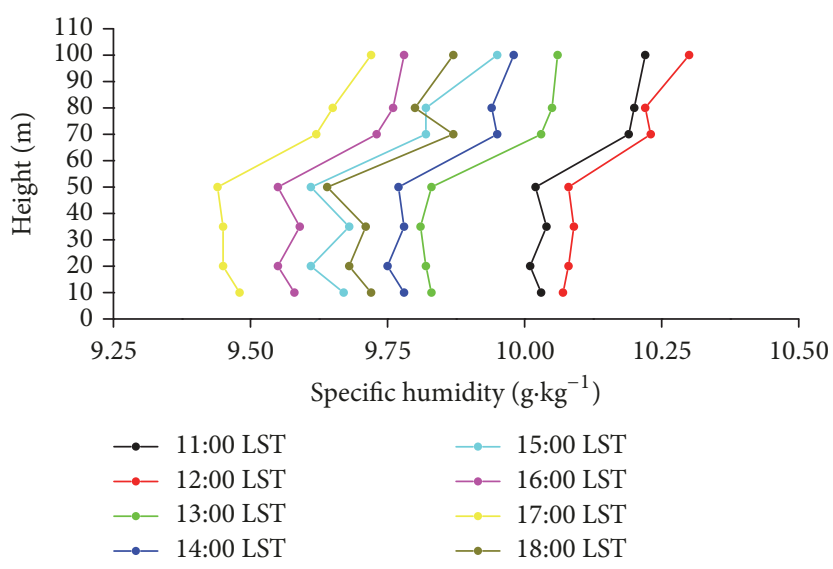

Figure 5: Vertical profiles of the average specific humidity at different times in Figure 4.

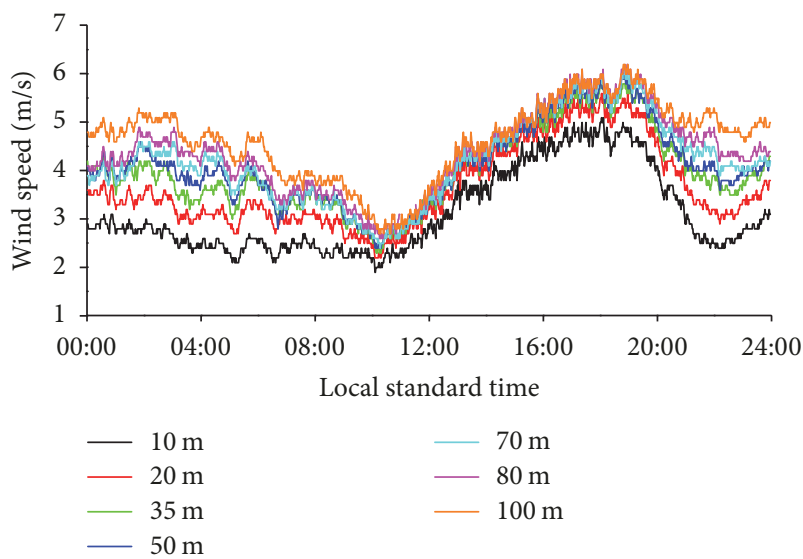

(a)

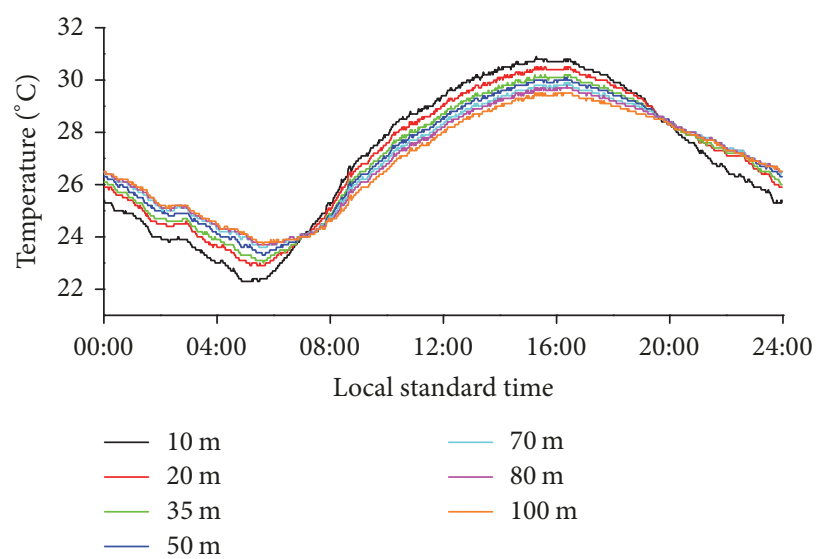

(b)

FIGURE 6: Similar to Figure 4, but regarding (a) the wind speeds and (b) the temperatures.

to calculate the bulk Richardson Number $\mathrm{Ri}_{b}$ during the observational period as follows:

$$
\mathrm{Ri}_{b}=\frac{g}{\Theta_{10}} \frac{\left(\Theta_{20}-\Theta_{10}\right)}{\left(U_{20}-U_{10}\right)^{2}} 10 .
$$

In (1), $g$ represents the gravitational acceleration; $\Theta_{20}$ represents the potential temperature at the height of $20 \mathrm{~m} ; \Theta_{10}$ represents the potential temperature at the height of $10 \mathrm{~m}$; $U_{20}$ represents the wind speed at the height of $20 \mathrm{~m}$; and $U_{10}$ represents the wind speed at the height of $10 \mathrm{~m}$. After averaging the calculation results, the mean diurnal change status of $\mathrm{Ri}_{b}$ was determined, as shown in Figure 7.

By comparing of Figures 6(b) and 7, it could be seen that the atmospheric turbulence over the Gobi Desert was mainly driven by thermal forcing. Due to the strong turbulent mixing during the transition period from the offshore to the onshore breezes, the minimum vertical gradient of the wind speed was found to occur in the midmorning in the study area.

3.2. A Case Study. In this study, August 12 was chosen as a case study for the atmospheric boundary layer and local

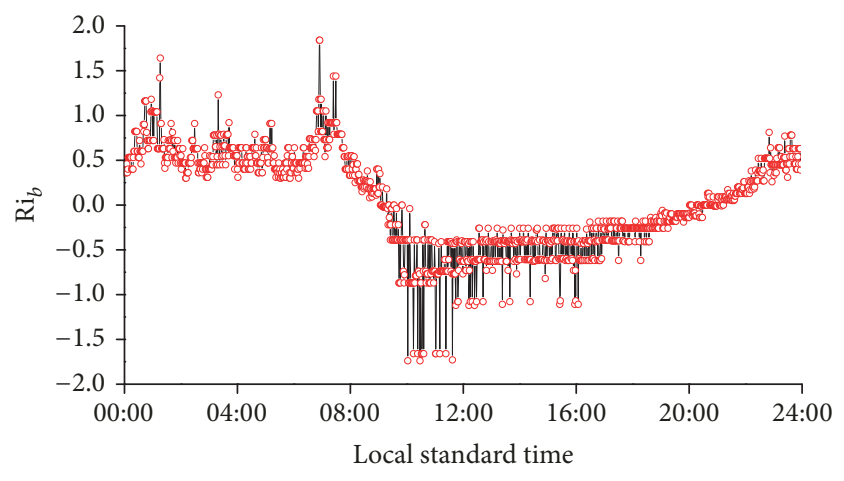

Figure 7: Average temporal change curve of the bulk Richardson Number $\mathrm{Ri}_{b}$ calculated from the tower observations through the observational period.

circulation analyses, due to the absence of any major synoptic forcing following the precipitation on August 8.

Figure 8 shows the wind profile with a height of less than $2 \mathrm{~km}$ from the ground, while Figure 9 presents the potential temperature and specific humidity profiles with a height less 


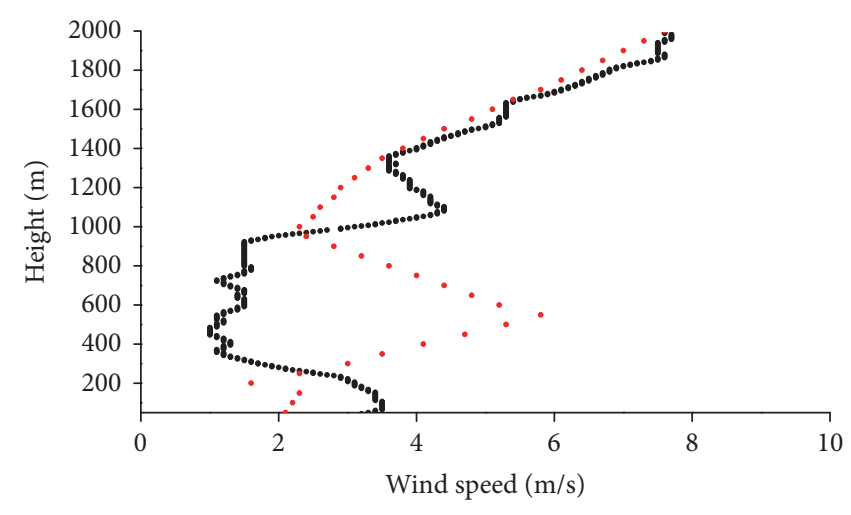

- GPS sonde

- Radiosonde

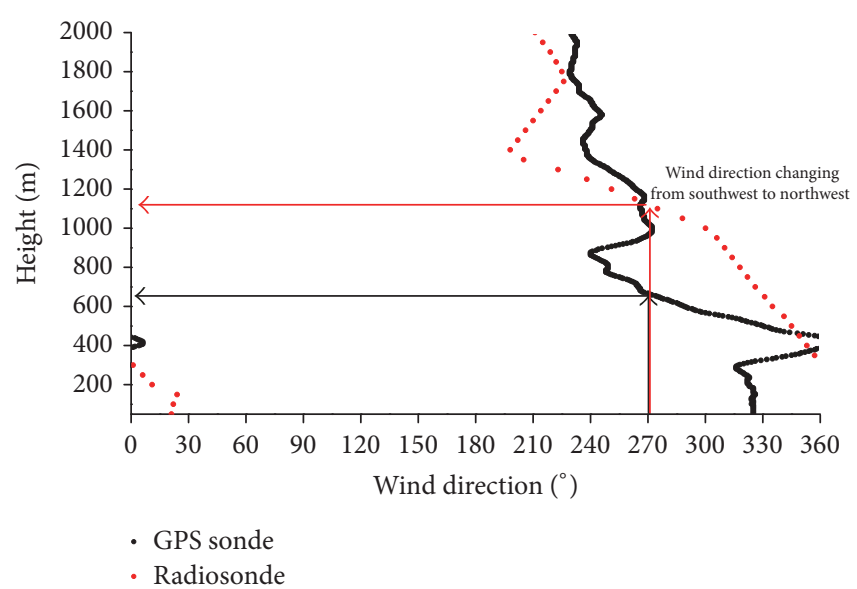

(b)

FIGURE 8: Profiles of (a) the wind speed and (b) the wind direction, which were derived from the measurements of the GPS sonde (black dot) and radiosonde (red dot) at 12:00 LST on August 12th.

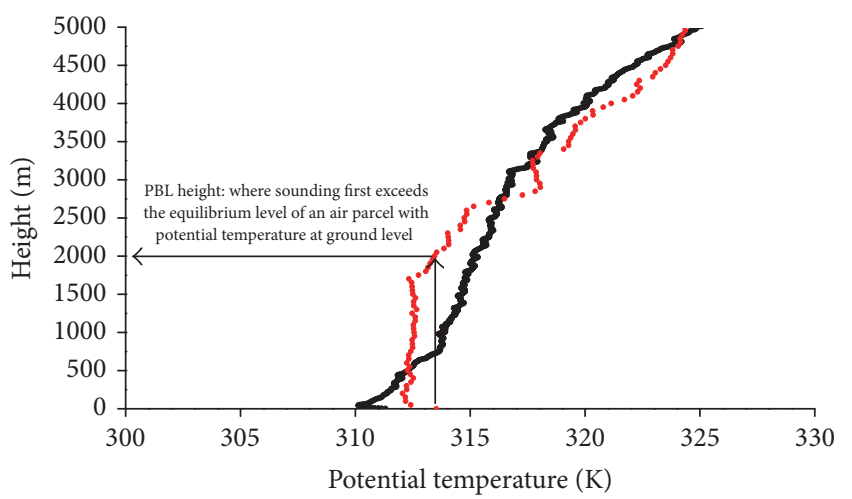

- GPS sonde

- Radiosonde

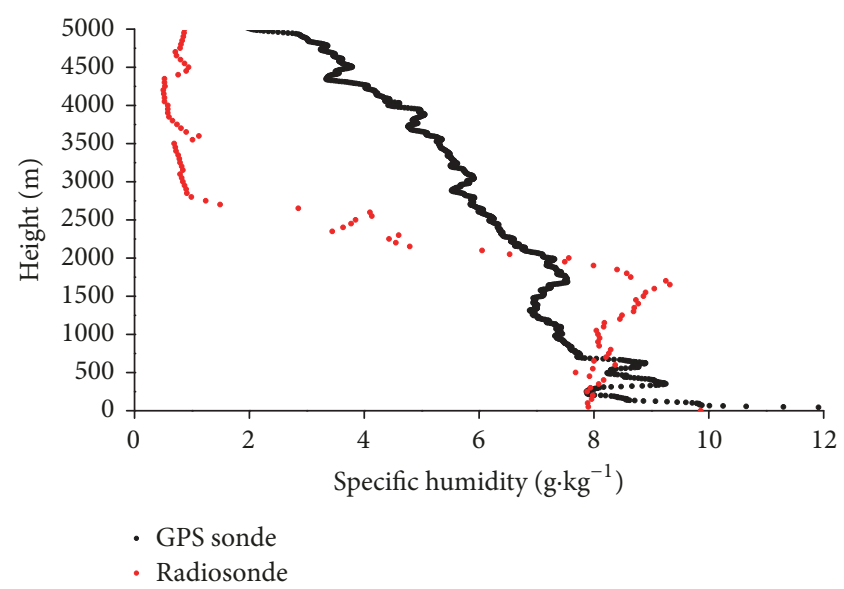

(b)

FIgURE 9: Similar to Figure 8, but regarding (a) the potential temperature and (b) the specific humidity.

than $5 \mathrm{~km}$ from the ground, at 12:00 on August 12. The GPS sonde and radiosonde were recorded at the lakeshore and southern Gobi Desert, respectively. It can be seen from Figure 8 that the boundary layer wind field was obviously affected by onshore breezes in study area. For example, the large-scale flow accounted for southwesterly winds (from $200^{\circ}$ to $270^{\circ}$ ) with heights between 1 and $2 \mathrm{~km}$, while the wind direction changed from southwest to northwest at approximately $650 \mathrm{~m}$ at the lakeshore. As the onshore breezes penetrated further inland, the breeze impacting heights were observed to rise. When reaching the location of the radiosonde radar, the wind direction changing height was determined to be approaching approximately $1.1 \mathrm{~km}$.

The height of the ABL is also a fundamental parameter to characterize the structure of the lower troposphere. Under convective conditions, the ABL height is often identified with the base of an elevated inversion or stable layer or as the height of a significant reduction in air moisture [24]. The thetaincrease method was often applied for the determination of the ABL height [25-27]. It can be seen from Figure 9 that a perfectly mixed $\mathrm{ABL}$ existed at the location of the radiosonde radar and the depth of the convective boundary layer was about $2 \mathrm{~km}$. During the observation campaign, the midday $\mathrm{ABL}$ at the location of the radiosonde radar could exceed $3 \mathrm{~km}$ or even higher (measurements are not shown), which was a result of vigorous turbulent mixing in the Gobi Desert [28]. However, due to the cold-lake effect of Bosten Lake, the lakeshore atmospheric turbulent mixing was inhibited. In this sounding, the moisture transition layer is not clear at the lakeshore and the base of the stable layer, where potential temperature begins increasing significantly, extended nearly to the ground. In addition, the lakeshore humidity layer was observed to be obviously higher than that of the southern Gobi area, which can potentially reach to approximately $6 \mathrm{~km}$.

The outputs of the high resolution WRF simulation were used for distinguishing the breeze circulation around Bosten Lake. Figure 10 shows the horizontal distribution of the wind 


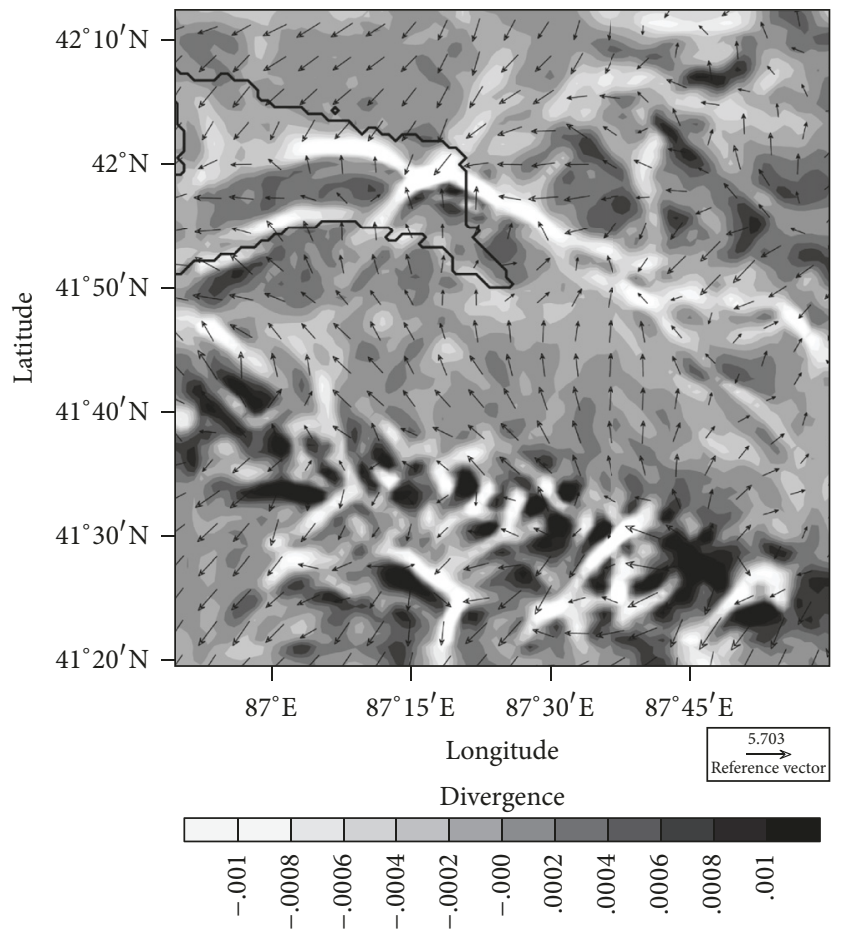

(a)

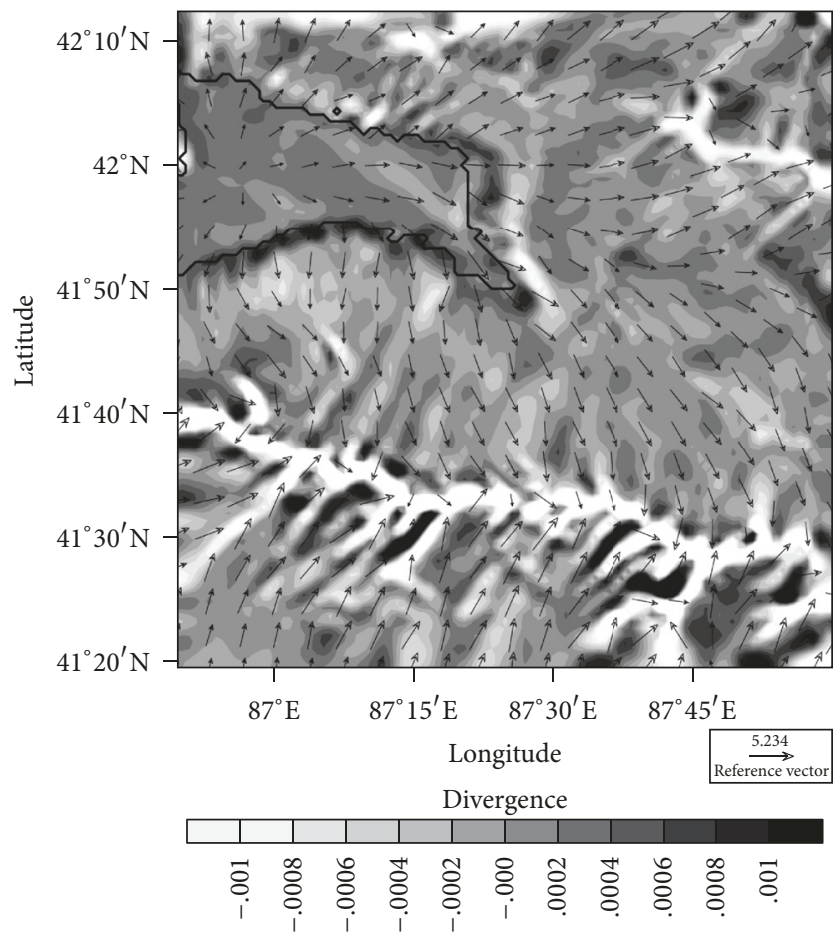

(c)

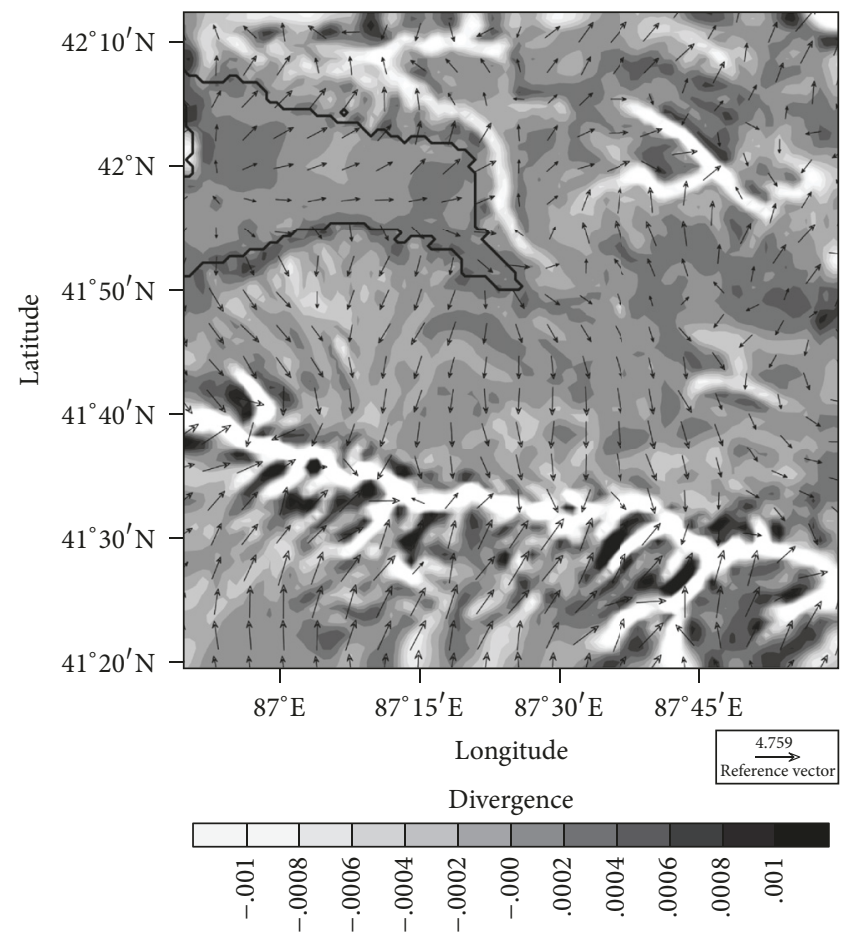

(b)

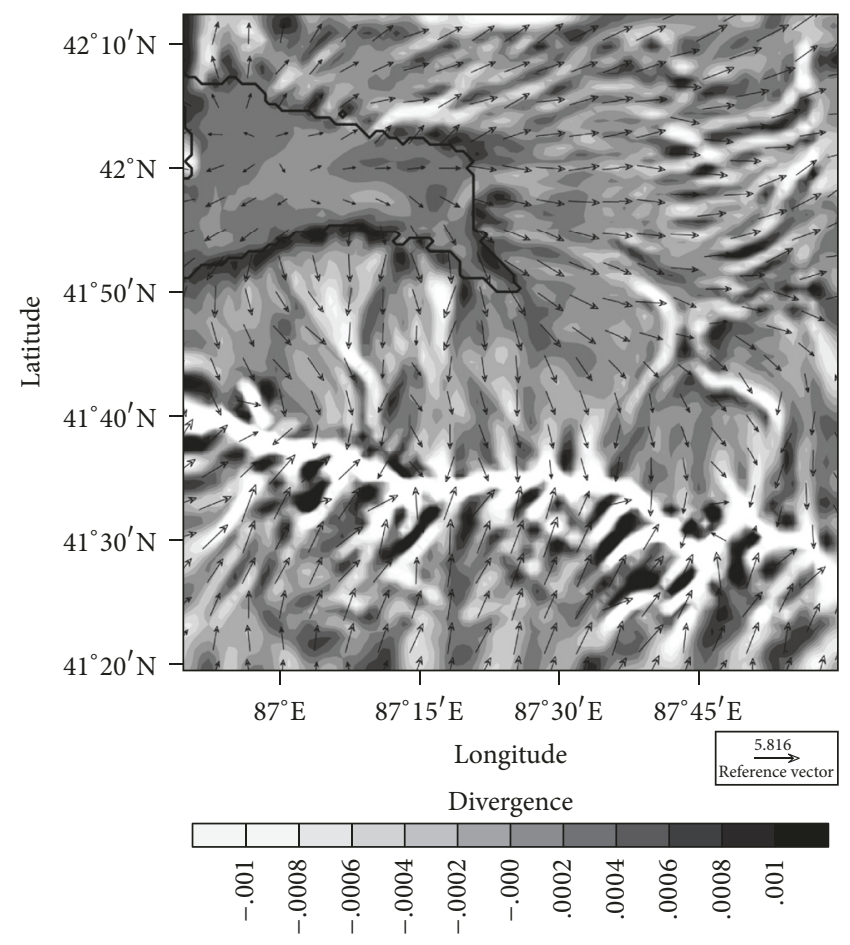

(d)

FIGURE 10: Horizontal distribution of the wind flow and divergence at the height of 10 m over D4 of the WRF simulation: (a) 23:00 LST, August 11; (b) 10:00 LST, August 12; (c) 12:00 LST, August 12; (d) 14:00 LST, August 12. Note. The area enclosed by black solid lines represents Bosten Lake. 


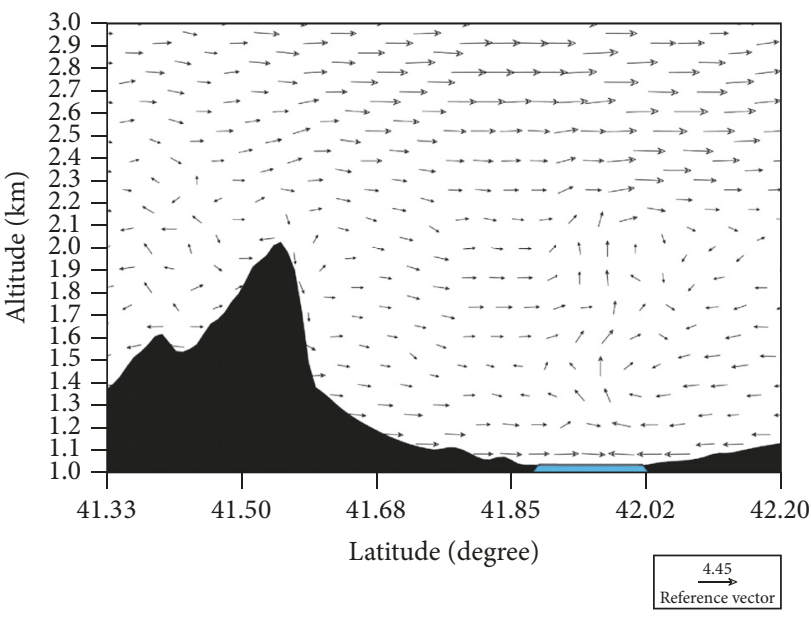

(a)

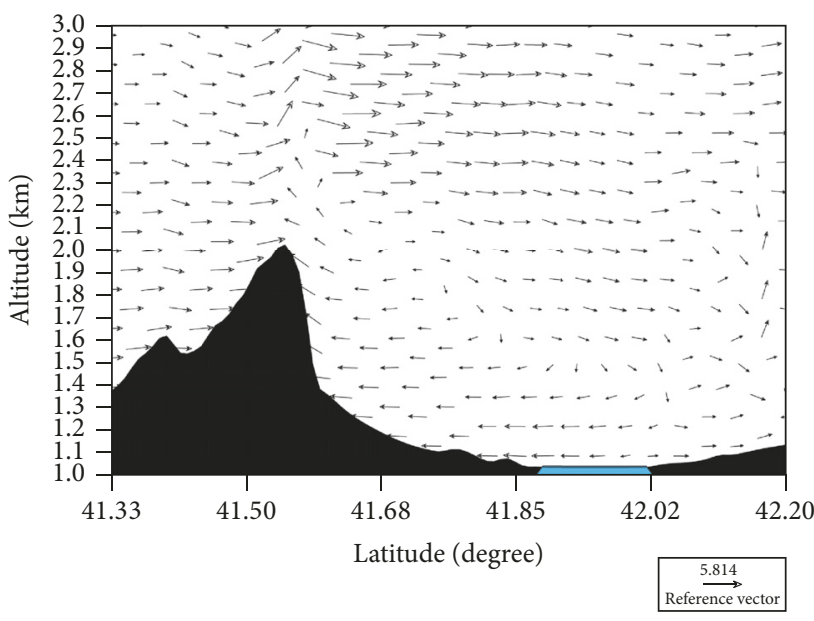

(c)

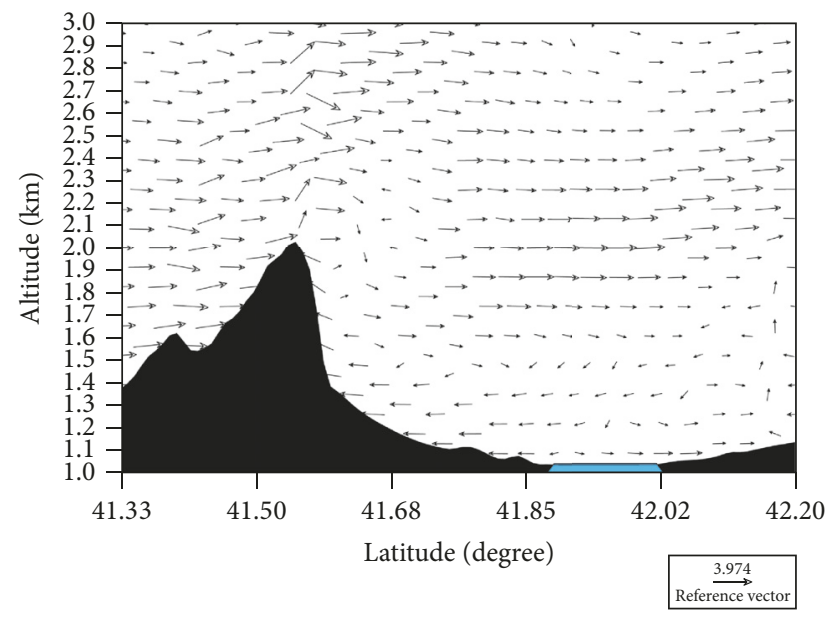

(b)

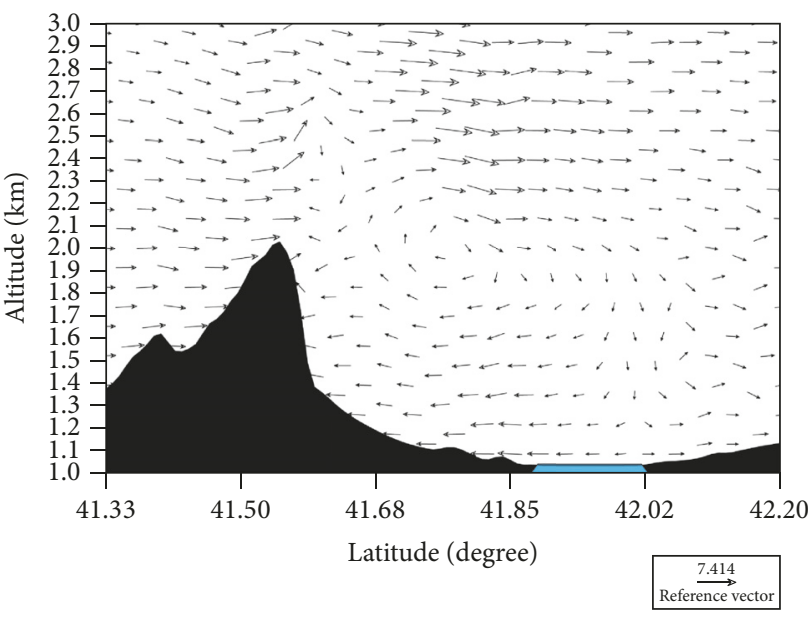

(d)

FIGURE 11: Wind field vertical cross-section at altitudes less than $3 \mathrm{~km}$, drawn along $87^{\circ} 19^{\prime} \mathrm{E}$ over D4 of the WRF simulation: (a) $23: 00$ LST, August 11; (b) 10:00 LST, August 12; (c) 12:00 LST, August 12; (d) 14:00 LST, August 12. Note. The terrain is filled in black, and the lake surface is filled in blue.

flow and the divergence at the height of $10 \mathrm{~m}$ over the inner domain for the midnight and midday wind flows. Figure 11 presents the wind field vertical cross-section with altitudes less than $3 \mathrm{~km}$, where the profile was drawn along $87^{\circ} 19^{\prime} \mathrm{E}$. In Figure 11, the vertical velocity of the airflow is multiplied by a weighting factor of 2 , in order to show the vertical structure of the breeze circulations more significantly.

It was determined in this study that two figures clearly indicated the diurnal evolution of the atmospheric circulation in Bosten Lake area. Under the influence of the nighttime mountain-valley winds from the surrounding mountain slopes, the near-surface airflow diverted to Bosten Lake, and a convergence front was formed at the lake's surface (Figure 10(a)). Then, the airflow was forced to rise, and a small circulation cell could be identified (Figure 11(a)).

It was observed that the airflow field at the surface shifted to an almost opposite direction at noon under the control of more intense and higher onshore breezes. Meanwhile, the lake's surface was transitioned to a divergence center (Figures 10(b)-10(d)). With the prominent upward motion of the air flow along the ridge line of the Kuruketage Mountains in the south, the lake's surface was under the influence of a subsidence flow. At 10:00 LST, the heights of the onshore breezes were less than $300 \mathrm{~m}$, with no obvious atmospheric circulation. However, two hours later, the onshore breezes in the southern Gobi area extended up to approximately $600 \mathrm{~m}$ in height, until 14:00 LST, the onshore breeze intensity was further strengthened to form a larger circulation cell than those during the nighttime (Figures 11(b)-11(d)). It is worth noting that the atmospheric movements of the circulation cells shown in Figure 11 are all clockwise, which indicated a relationship with the synoptic winds. Moreover, the Kuruketage Mountains elongate in the direction perpendicular to the breeze, which effectively blocked the low-level large-scale flows from passing around Bosten Lake, thereby creating a favorable condition for the diurnal evolution of the local breeze circulations. 


\section{Conclusions}

In this study, the physical characteristics of low atmosphere in the Gobi area adjacent to Bosten Lake during the summer season of 2016 were examined. For this purpose, a monthlong field observation campaign was conducted which covered approximately $100 \mathrm{~km}^{2}$ of the Gobi Desert. Also, the WRF model was used to simulate the diurnal evolution of the breeze circulations over the lake area for a specific case study. The main purpose of the present study was to discuss and analyze the influences of large lakes on the local climate in the arid Gobi Desert of northwestern China.

The analysis of the data was mainly focused on dynamic and thermal characteristics of the lower atmosphere. The surface meteorological variables were measured using five meteorological stations. An analysis of the surface wind direction distribution as a function of the time of day revealed the daily patterns of the local wind regime. Then, a comparison of the wind speeds, temperatures, and specific humidity revealed the intensity and travelling extent of the onshore breezes, as well as the cold-lake effects of Bosten Lake. This study's analysis of the meteorological tower measurements showed the diurnal evolution of stratification and turbulent activities in the atmospheric near-surface layer. A comparison of the lakeshore sounding and Gobi Desert sounding revealed the impact of Bosten Lake on the boundary layer structure. This study focused on the diurnal evolution of the local atmospheric circulations using the WRF model for the dynamical downscaling of the NCEP reanalysis data to $1 \mathrm{~km}$. Then, the low-level airflow fields around Bosten Lake were effectively distinguished.

The conclusions of this study are summarized as follows:

(1) Due to cold-lake effects of Bosten Lake during the daytime, a strong thermal gradient at the surface of study area was observed, which favored the triggering of onshore breezes. The daytime turbulent activities at the lakeshore were also inhibited, and a nonperfectly mixed ABL existed.

(2) The onshore breezes dominated the local surface wind regime by a horizontal extent of more than $7 \mathrm{~km}$ from the lakeshore, with a peak average wind speed reaching approximately $5 \mathrm{~m} / \mathrm{s}$. The vertical gradient of the near-surface wind speed was influenced not only by the atmospheric turbulence mixing but also by the transition between the nocturnal and onshore breezes. The onshore breezes were also found to play a major role in the vertical structure of the local atmospheric boundary layer.

(3) Due to the continuous daytime advection of water vapor, a positive horizontal humidity gradient existed from the lakeshore to the southern Gobi Desert. Also, an isohumidity layer at heights between 10 and $50 \mathrm{~m}$ a.g.l. was observed in the atmospheric near-surface layer from 11:00 to 18:00 LST. In addition, the lakeshore's humidity layer was significantly higher than that of the southern Gobi Desert.

(4) The numerical simulation showed that a day-night alternating local atmospheric circulation existed in the Bosten Lake area. During the nighttime, the ground flow field diverted to Bosten Lake, and a convergence front was formed on the lake's surface. At midday, under the control of strong onshore breezes, the lake's surface transitioned into a divergence center, accompanied by a subsidence flow. The intensity and height of the midday breeze circulations were more prominent than those of the nighttime. In addition, the regional topography provided favorable conditions for the diurnal evolution of the local breeze circulations.

The results of this study showed that, during summer periods in the arid Gobi Desert areas of northwestern China, the existence of large lakes significantly altered the physical characteristics of the local lower atmosphere. Therefore, it was confirmed that these lakes play a positive role in the local climate. The next step will be completely further research during other seasons.

\section{Conflicts of Interest}

The authors declare that there are no conflicts of interest regarding the publication of this paper.

\section{References}

[1] Z. Wu, H. Zhang, C. M. Krause, and N. S. Cobb, "Climate change and human activities: a case study in Xinjiang, China," Climatic Change, vol. 99, no. 3, pp. 457-472, 2010.

[2] H. B. Ling, H. L. Xu, J. Y. Fu, Q. Q. Zhang, and X. W. Xu, "Analysis of temporal-spatial variation characteristics of extreme air temperature in Xinjiang, China," Quaternary International, vol. 282, pp. 14-26, 2012.

[3] X. Li, F. Jiang, L. Li, and G. Wang, "Spatial and temporal variability of precipitation concentration index, concentration degree and concentration period Xinjiang, China," International Journal of Climatology, vol. 31, no. 11, pp. 1679-1693, 2011.

[4] C. C. Xu, Y. N. Chen, Y. H. Yang, X. Hao, and Y. Shen, "Hydrology and water resources variation and its response to regional climate change in Xinjiang," Journal of Geographical Sciences, vol. 20, no. 4, pp. 599-612, 2010.

[5] H. Huang, Y. Han, M. Cao, J. Song, and H. Xiao, "Spatialtemporal variation of aridity index of China during 1960-2013," Advances in Meteorology, vol. 2016, Article ID 1536135, 10 pages, 2016.

[6] M. Guo, W. Wu, X. Zhou, Y. Chen, and J. Li, "Investigation of the dramatic changes in lake level of the Bosten Lake in northwestern China," Theoretical and Applied Climatology, vol. 119, no. 1-2, pp. 341-351, 2015.

[7] B. Jiang, Y.-Y. Chen, E.-M. Rao, L. Zhang, and Z.-Y. Ouyang, "Final ecosystem services valuation of Bosten Lake," Chinese Journal of Ecology, vol. 34, no. 4, pp. 1113-1120, 2015.

[8] J. Siebert, U. Sievers, and W. Zdunkowski, "A one-dimensional simulation of the interaction between land surface processes and the atmosphere," Boundary Layer Meteorology, vol. 59, no. 1-2, pp. 1-34, 1992.

[9] D. Courault, P. Drobinski, Y. Brunet, P. Lacarrere, and C. Talbot, "Impact of surface heterogeneity on a buoyancy-driven convective boundary layer in light winds," Boundary Layer Meteorology, vol. 124, no. 3, pp. 383-403, 2007.

[10] Y. Shao, S. Liu, J. H. Schween, and S. Crewell, "Largeeddy atmosphere-land-surface modelling over heterogeneous surfaces: model development and comparison with measurements," Boundary Layer Meteorology, vol. 148, no. 2, pp. 333356, 2013. 
[11] S.-L. Kang and D. H. Lenschow, "Temporal evolution of lowlevel winds induced by two-dimensional mesoscale surface heat-flux heterogeneity," Boundary Layer Meteorology, vol. 151, no. 3, pp. 501-529, 2014.

[12] P. Samuelsson and M. Tjernström, "Mesoscale flow modification induced by land-lake surface temperature and roughness differences," Journal of Geophysical Research: Atmospheres, vol. 106, no. D12, pp. 12419-12435, 2001.

[13] S. M. S. Stivari, A. P. de Oliveira, H. A. Karam, and J. Soares, "Patterns of local circulation in the Itaipu Lake Area: Numerical simulations of lake breeze," Journal of Applied Meteorology, vol. 42, no. 1, pp. 37-50, 2003.

[14] M. A. Hernández-Ceballos, J. A. Adame, J. P. Bolívar, and B. A. De la Morena, "A mesoscale simulation of coastal circulation in the Guadalquivir valley (southwestern Iberian Peninsula) using the WRF-ARW model," Atmospheric Research, vol. 124, no. 5, pp. 1-20, 2013.

[15] C. Turrent and O. Zaitsev, "Seasonal cycle of the near-surface diurnal wind field over the bay of La Paz, Mexico," Boundary Layer Meteorology, vol. 151, no. 2, pp. 353-371, 2014.

[16] A. N. Comin and O. C. Acevedo, "Numerical simulation of sea breeze convergence over Antarctic Peninsula," Advances in Meteorology, vol. 2017, Article ID 7686540, 11 pages, 2017.

[17] S. Federico, L. Pasqualoni, L. de Leo, and C. Bellecci, "A study of the breeze circulation during summer and fall 2008 in Calabria, Italy," Atmospheric Research, vol. 97, no. 1-2, pp. 1-13, 2010.

[18] T. Qian, C. C. Epifanio, and F. Zhang, "Topographic effects on the tropical land and sea breeze," Journal of the Atmospheric Sciences, vol. 69, no. 1, pp. 130-149, 2012.

[19] W. C. Skamarock, J. B. Klemp, J. Dudhia et al., "A description of the advanced research WRF Version 3," NCAR Technical Note NCAR/TN 475, 2008.

[20] T. T. Warner, Numerical Weather and Climate Prediction, Cambridge University Press, New York, NY, USA, 2011.

[21] X.-M. Hu, J. W. Nielsen-Gammon, and F. Zhang, "Evaluation of three planetary boundary layer schemes in the WRF model," Journal of Applied Meteorology and Climatology, vol. 49, no. 9, pp. 1831-1844, 2010.

[22] H. H. Shin and S.-Y. Hong, "Intercomparison of planetary boundary-layer parametrizations in the WRF model for a single day from CASES-99," Boundary Layer Meteorology, vol. 139, no. 2, pp. 261-281, 2011.

[23] X.-M. Hu, P. M. Klein, and M. Xue, "Evaluation of the updated YSU planetary boundary layer scheme within WRF for wind resource and air quality assessments," Journal of Geophysical Research: Atmospheres, vol. 118, no. 18, pp. 10490-10505, 2013.

[24] P. Seibert, F. Beyrich, S.-E. Gryning, S. Joffre, A. Rasmussen, and P. Tercier, "Review and intercomparison of operational methods for the determination of the mixing height," Atmospheric Environment, vol. 34, no. 7, pp. 1001-1027, 2000.

[25] G. C. Holzworth, "Estimates of mean maximum mixing depths in the contiguous United States," Monthly Weather Review, vol. 92, no. 5, pp. 235-242, 1964.

[26] F. J. Marsik, K. W. Fischer, T. D. McDonald, and P. J. Samson, "Comparison of methods for estimating mixing height used during the 1992 Atlanta Field Intensive," Journal of Applied Meteorology and Climatology, vol. 34, no. 8, pp. 1802-1814, 1995.

[27] J. W. Nielsengammon, C. L. Powell, M. J. Mahoney et al., "Multisensor estimation of mixing heights over a coastal city," Journal of Applied Meteorology \& Climatology, vol. 47, no. 1, pp. 27-43, 2008.
[28] M. Ma, Z. Pu, S. Wang, and Q. Zhang, "Characteristics and numerical simulations of extremely large atmospheric boundary-layer heights over an arid region in north-west China," Boundary Layer Meteorology, vol. 140, no. 1, pp. 163-176, 2011. 

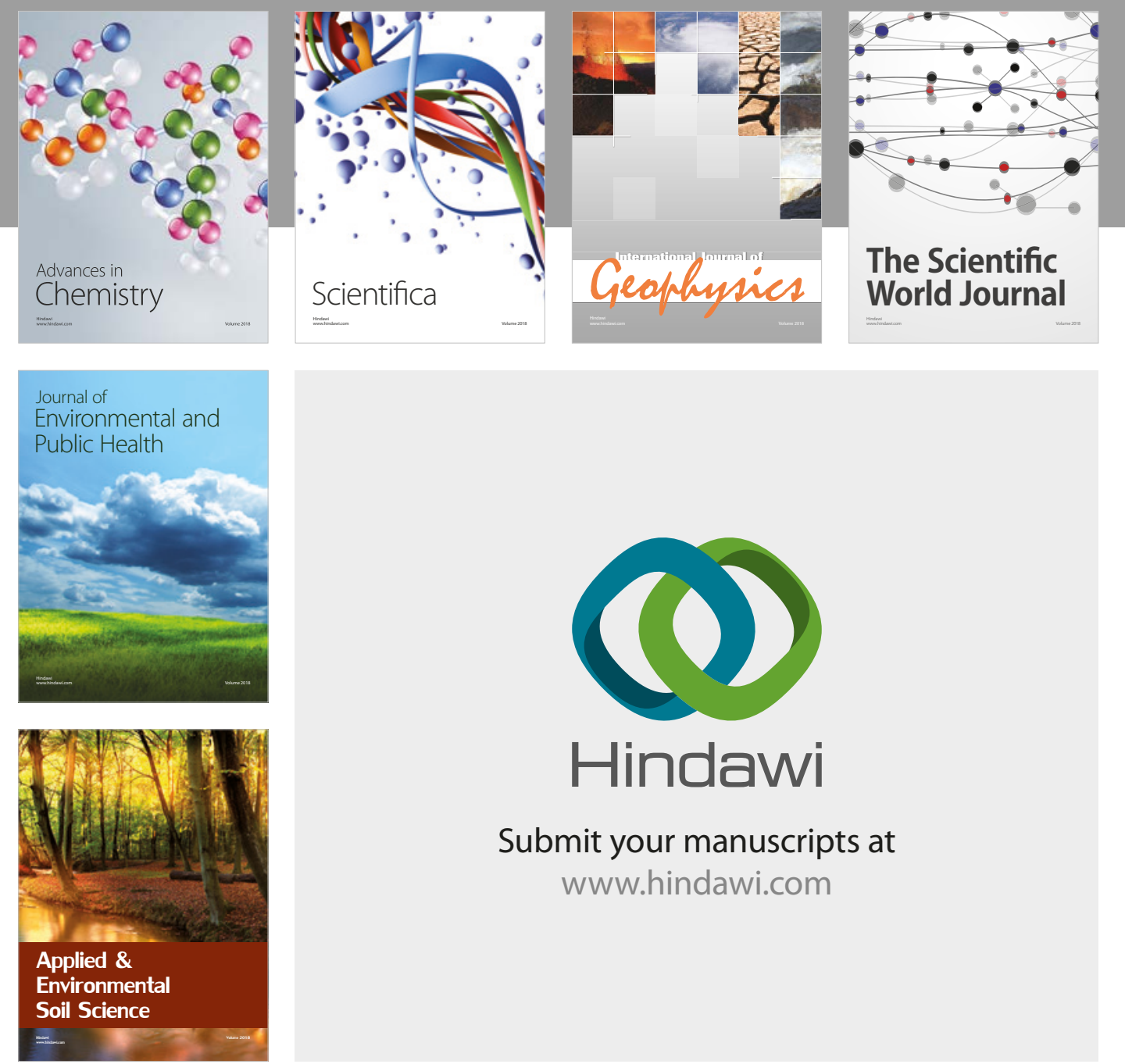

The Scientific

\section{World Journal}
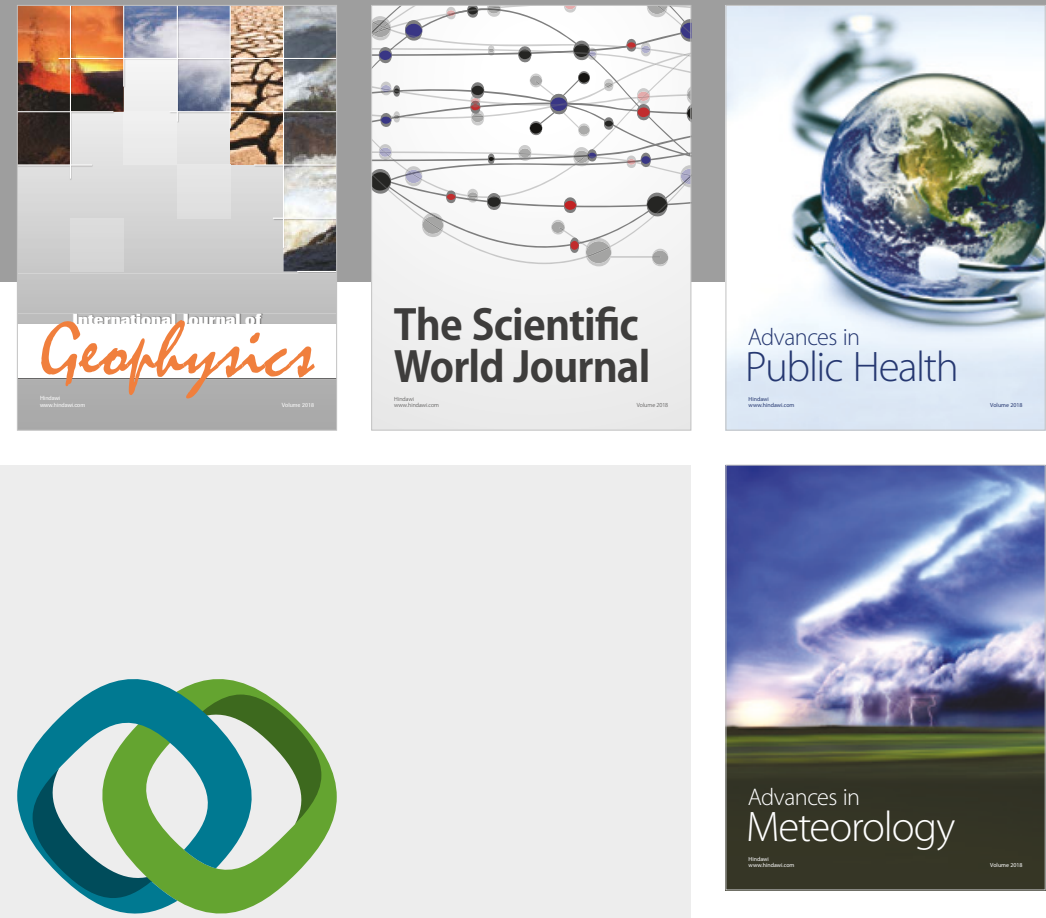

Advan

Public Health

\section{Hindawi}

Submit your manuscripts at

www.hindawi.com
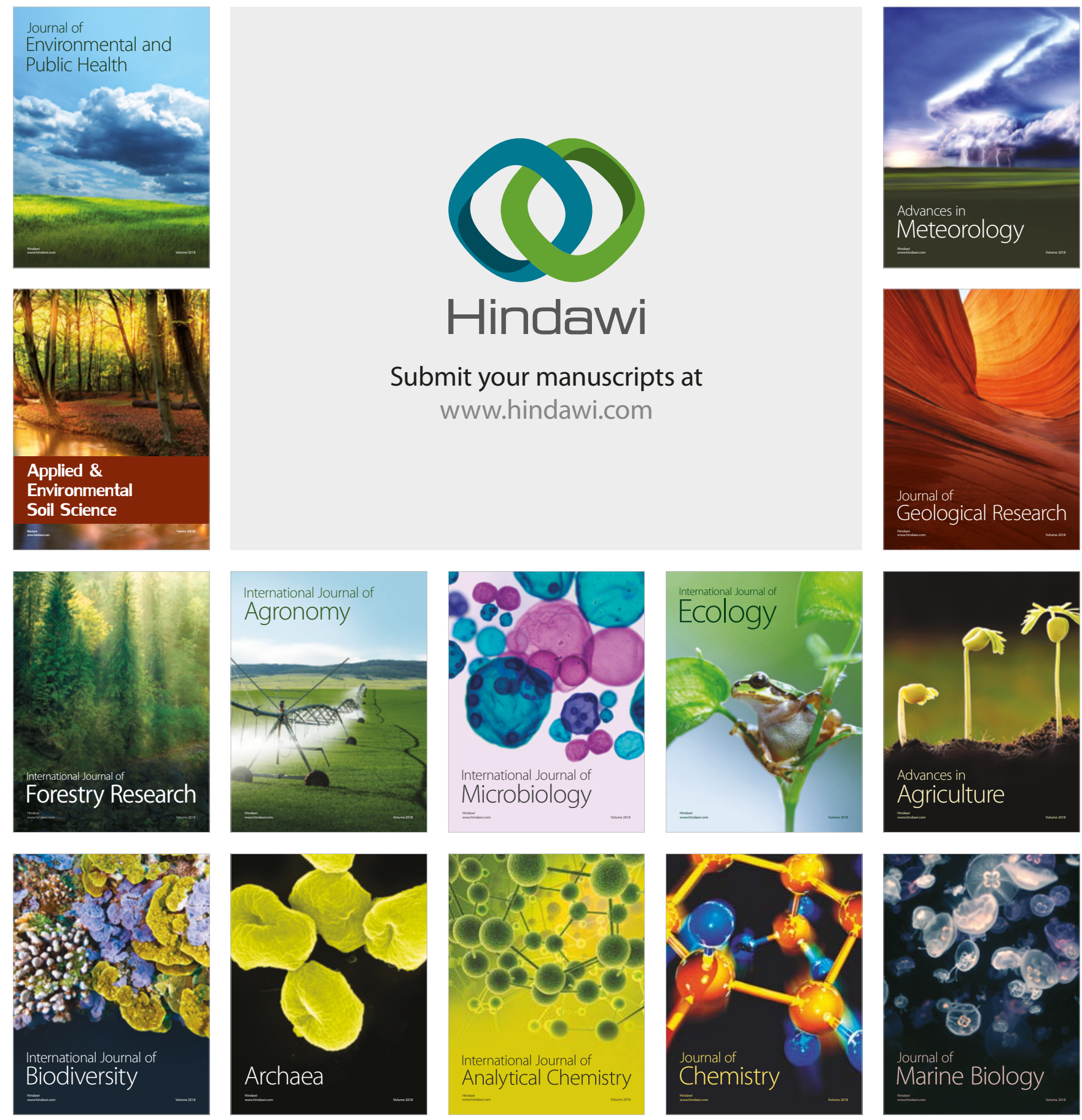